\title{
Erratum to: draft sequencing and assembly of the genome of the world's largest fish, the whale shark: Rhincodon typus smith 1828
}

\author{
Timothy D. Read ${ }^{1,2}$, Robert A. Petit III,2, Sandeep J. Joseph ${ }^{1,2}$, Tauqeer Alam ${ }^{1,2}$, M. Ryan Weil ${ }^{1,2}$, Maida Ahmad ${ }^{1,2}$, \\ Ravila Bhimani ${ }^{1,2}$, Jocelyn S. Vuong ${ }^{1,2}$, Chad P. Haase ${ }^{1,2}$, D. Harry Webb ${ }^{3}$, Milton Tan ${ }^{1,2^{*}}$ and Alistair D.M. Dove ${ }^{3}$
}

\section{Erratum:}

After publication of the original article [1], the authors noted that the following errors had occurred:

1. The following figure captions were in the incorrect order:

- Figure 3: The current caption for Fig. 3 is incorrect and should be the caption for Fig. 4.

The correct Figure legend should be: Overview of taxonomy of whale shark protein best matches to the $\mathrm{nr}$ database. Figure was constructed from best BLAST matches to the nr database using Krona [31] tool.

A fully updated Figure including the revised caption is included with this Erratum (Corrected Figure 3).

- Figure 4: The current caption for Fig. 4 is incorrect and should be the caption for Fig. 5 .

The correct Figure legend should be: Overview of best matches to the protein database that map to the Chordata taxonomy group.

A fully updated Figure including the revised caption is included with this Erratum (Corrected Figure 4).

- Figure 5: The current caption for Fig. 5 is incorrect and should be the caption for Fig. 3 .
The correct Figure legend should be: Phylogeny based on alignment of conserved single-copy proteins. Silhouettes are not to scale. Accessions: Petromyzon: GCA_000148955.1, Callorhinchus: GCA_000165045.2, Latimeria: GCA_000225785.1, Danio: GCA_00000203 5.3, Gadus: GCA_000231765.1, Gasterosteus: GCA 000180675.1, Oryzias: version MEDAKA1 (Ensembl), Oreochromis: GCA_000188235.1, Takifugu: GCA_000 180615.2, Tetraodon: GCA_000180735.1. Silhouette credits: Petromyzon by Gareth Monger, CC-BY; Callorhinchus by Tony Ayling, CC-BY-SA; Rhincodon by Scarlet23, vectorized by T. Michael Keesey, CC-BYSA; Latimeria by Maija Karala, CC-BY-NC-SA; Gadus, Oreochromis, Tetraodon, Gasterosteus by Milton Tan; Danio, Oryzias, Takifugu, no copyright.

A fully updated Figure including the revised caption is included with this Erratum (Corrected Figure 5).

2. All mentions of the GenBank ID LVEK00000000 are incorrect, and should be LVEK00000000.1. This was present in both Table 1 of the original article, and in the Availability of Data and Materials section. In updated version of Table 1 (Corrected Table 1) has been included with this Erratum.

The original article has also been corrected.

\footnotetext{
* Correspondence: milton.tan@emory.edu

1 Department of Medicine, Division of Infectious Diseases, Emory University School of Medicine, 1760 Haygood Drive, Atlanta, GA 30322, USA

${ }^{2}$ Department of Human Genetics, Emory University School of Medicine, 1760

Haygood Drive, Atlanta, GA 30322, USA

Full list of author information is available at the end of the article
} 


\section{Corrected Fig. 3:}

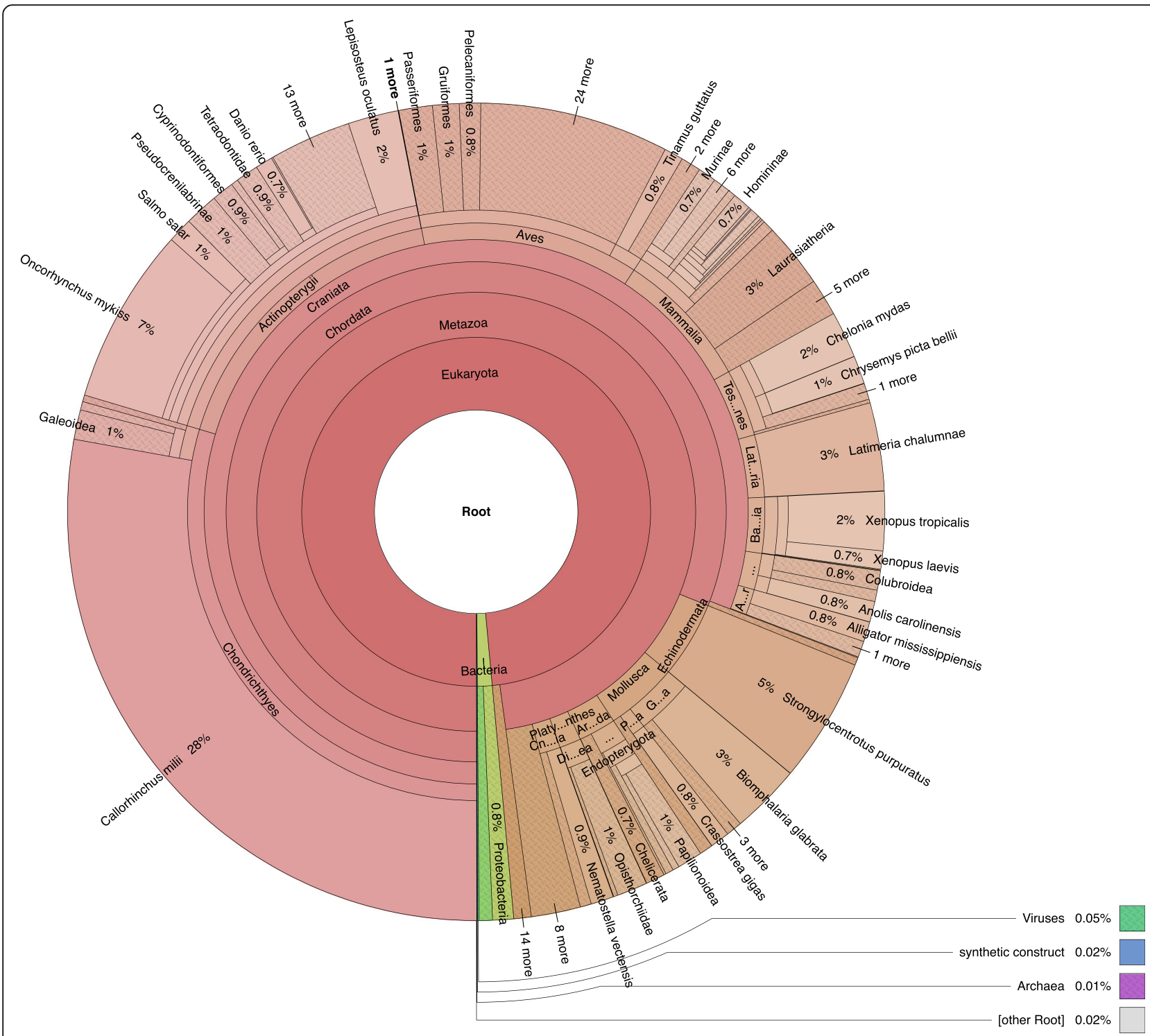

Fig. 3 Overview of taxonomy of whale shark protein best matches to the $\mathrm{nr}$ database. Figure was constructed from best BLAST matches to the nr database using Krona [31] tool 


\section{Corrected Fig. 4:}

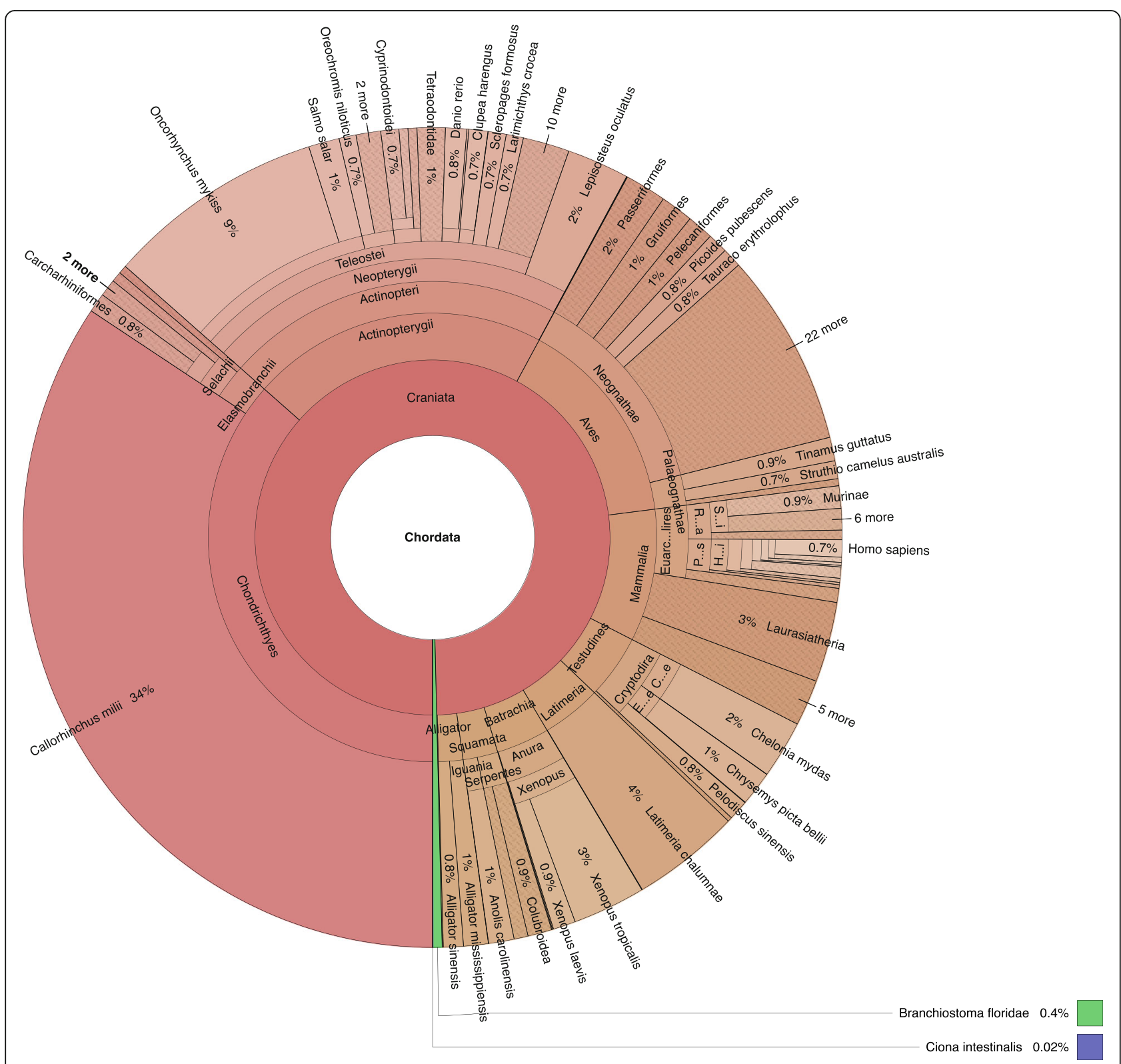

Fig. 4 Overview of best matches to the protein database that map to the Chordata taxonomy group 


\section{Corrected Fig. 5:}

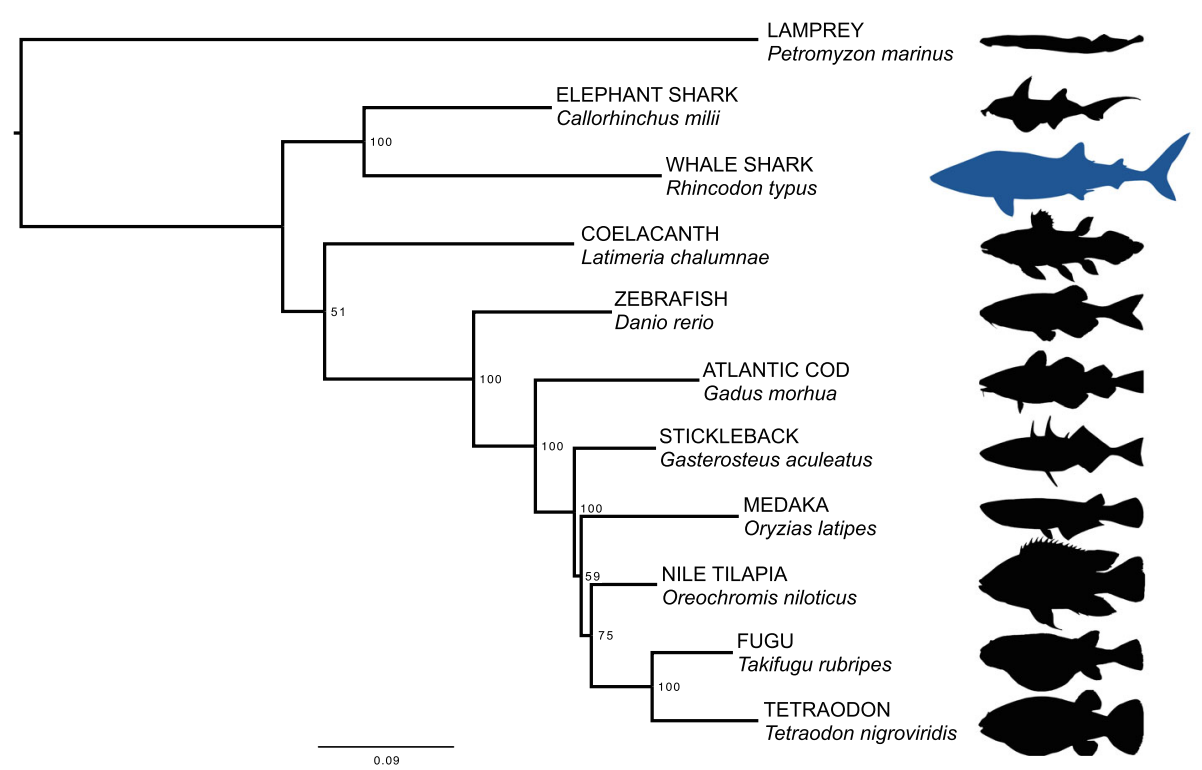

Fig. 5 Phylogeny based on alignment of conserved single-copy proteins. Silhouettes are not to scale. Accessions: Petromyzon: GCA_000148955.1, Callorhinchus: GCA_000165045.2, Latimeria: GCA_000225785.1, Danio: GCA_000002035.3, Gadus: GCA_000231765.1, Gasterosteus: GCA_000180675.1, Oryzias: version MEDAKA1 (Ensembl), Oreochromis: GCA_000188235.1, Takifugu: GCA_000180615.2, Tetraodon

\section{Corrected Table 1:}

Table 1 Project information

\begin{tabular}{ll}
\hline Property & Term \\
\hline Finishing quality & High quality draft \\
$\begin{array}{l}\text { Libraries used } \\
\text { Sequencing } \\
\text { platforms }\end{array}$ & Illumina: paired end library; 454: single end library \\
Fold coverage & 30x \\
Assemblers & SOAPdenovo (v. 2.04) \\
$\begin{array}{l}\text { Gene calling } \\
\text { method }\end{array}$ & $\begin{array}{l}\text { AUGUSTUS. Proteins matched against the NCBI nr } \\
\text { database using BLASTP, and the INTERPRO profile } \\
\text { database using InterProScan }\end{array}$ \\
Genbank ID & LVEKO0000000.1 \\
GenBank Date of & 5.11.2016 \\
Release & GP0102394 \\
GOLD ID & PRJNA255419 \\
BIOPROJECT &
\end{tabular}

\section{Author details}

${ }^{1}$ Department of Medicine, Division of Infectious Diseases, Emory University

School of Medicine, 1760 Haygood Drive, Atlanta, GA 30322, USA.

${ }^{2}$ Department of Human Genetics, Emory University School of Medicine, 1760 Haygood Drive, Atlanta, GA 30322, USA. ${ }^{3}$ Georgia Aquarium, 225 Baker Street, Atlanta, GA 30313, USA.

Received: 11 September 2017 Accepted: 11 September 2017

Published online: 25 September 2017

\section{Reference}

1. Read TD, Petit RA III, Joseph SJ, Alam MT, Weil MR, Ahmad M, Bhimani R, Vuong J, Haase CP, Webb DH, Tan M, Dove ADM. Draft sequencing and assembly of the genome of the world's largest fish, the whale shark: Rhincodon typus smith 1828. BMC Genomics. 2017;18:532. https://doi.org/10. 1186/s12864-017-3926-9. 